\title{
Impact of Marital Adjustment on Mental Health of Working Women
}

\author{
Sharmila Dhote \\ Assistant Professor, Department of Psychology, St. Andrew's College, Mumbai \\ Corresponding author: Ms. Sharmila Dhote
}

\begin{abstract}
Background: In India, marriage was once upon a time, considered a holy religious ceremony. Unfortunately, today, the institution of marriage is crumbling due to the adverse effects of globalization. Marriage as a major life-changing unit is definitely more challenging to women than men. The challenge becomes even more stressful for working women, who keep vacillating between their dual responsibilities. This paper focuses on the influence of Marital Adjustment on the Mental Health of working women in Mumbai.

Methods: 150 working women were selected by random sampling method from Mumbai across various occupations. The age range was from 26 to 35 years and the minimum educational qualification was graduation. The sample did not consider women who were divorced and also those who were widows.

Results: The results obtained indicate that there is a significant relationship between Marital Adjustment and Mental Health of women.

Conclusion: Findings recommended that marital therapists should consider some effective strategies to resolve marital conflicts and thereby improve the mental health of women.
\end{abstract}

Keywords: Marital Adjustment, Mental Health, Working Women.

(Paper received $-28^{\text {th }}$ December 2017, Peer review completed - $3^{\text {rd }}$ January 2018)

(Accepted $-6^{\text {th }}$ January 2018)

\section{INTRODUCTION}

Life today is full of stress and strain. In the so-called Global village, we practically live in an adulterated society in terms of the tangible and intangible goods we consume. They may be in the form of actual products, emotions, relationships etc. This has resulted in degradation of our health status. The popular proverb namely, 'Health is Wealth' has tremendous implications on the unhealthy lifestyles which are the by-products of Globalisation. It is the need of the hour that we prioritise attention to the dimension of health.

The concept of mental health pre-supposes a sound mind in a sound body. A mentally healthy person shows balanced behaviour and faces realities of life [1]. The expression "mental health" consists of two words mental and health. The word 'mental' usually implies something more than purely cerebral functioning of a person. It includes one's emotional affective states. It is the equilibrium in one's socio cultural context that is reflected by the relationship one establishes with others.

Health generally means a state of complete physical, mental and social well-being and not merely the absence of disease or infirmity [2]. Mental health is those behaviours, perceptions and feelings that determine a person's overall level of personal effectiveness, success, happiness and excellence of functioning as a person. It depends on the development and retention of goals that are neither to high not low to permit realistic successful maintenance of belief in one's self as worthy, effective human being [3]. 
Working women are generally expected to make several socio-familial adjustments, which in turn cause stress, anxiety and depression. Indian working women with their religious and cultural ideologies, norms and values are faced with severe adjustment problems. Some major problems that are encountered are lack of freedom, work overload, shifts schedule, late hour jobs, commuting hazards etc. Consequently, the overall adjustment process involving emotional stability, tolerance capacity and some other personality attributes face severe threat, which affect mental health negatively. If one can think properly, one can act purposefully. One needs to be in a sound frame of mind to carry out various family responsibilities, understand complexities, and adopt strategies to resolve problems.

Sinha and Mukerjee [4] define Marital adjustment as, "the state in which there is an overall feeling between husband and wife, of happiness and satisfaction with their marriage and with each other. This implies experiencing satisfactory relationship between spouses characterized by mutual concern, care, understanding and acceptance [4].

The interface between the work place and the family life is more stressful for the women who work outside the home since they have to perform both familial and professional roles [5]. The work life balance is directly reflected through the workplace structure. Work place flexibility is an important factor but limited to the high income and position of women, whereas for women who are low earners and have children to look after, it becomes very difficult to establish work life balance [6].

Previous research studies on the relationship between women employment and Marital adjustment and subsequently Mental health have produced conflicting results: some results indicate a positive relationship between women employment and marital adjustment whereas, others suggest a negative relationship.

Lloyd that found that socioeconomic status is a contributing factor to marital adjustment. He believed that the higher the income, the lower the chance of a divorce [7]. Nathawat and Mathur found that in respect of marital adjustment, working women reported significantly better marital adjustment and subjective wellbeing than housewives; they also scored higher than housewives in general health, life satisfaction and selfesteem measures [8].

The study by Nye and Hoffman, revealed that the employment of wives increased marital conflict. If the income of wife is equal to or exceeds that of the husband which is contrary to the norm, the wife's employment may become a cause of conflict, because of her superior economic position [9].

South is of the opinion that when women are employed, the probability of a divorce increases as they are economically independent. Also employed women, stand better chances of finding a partner as compared to the unemployed ones, as employment always brings you an opportunity to meet new people [10].

Hansen found that women who are unemployed have a greater probability of having a stressed martial relationship, which could be a reason for marriage dissolution. Unemployed women often in a dissatisfied marital relationship look out for employment, anticipating divorce [11]. Migon reported that working wives have marital problems, rising separation and divorce rates. Thus, such incidences are sources of stress in the lives of the husband, wife, as well as their children [12]. Gupta and Ganguli developed a marriage-work information schedule and administered it to 80 married women working as clerks in financial organizations in Delhi, India [13].

Results reveal the positive and negative effects of the marriage-work relationship. The negative effects of work on marriage were significantly greater than those of marriage on work. Subjects experienced the greatest conflict over the "mother" role.

Hemalatha and Suryanarayana studied the role interactions of 150 married working mothers in Tirupati, India, in varied fields of employment. It was found that wives had made more adjustments in family maintenance than did the husbands. However, most of them were able to combine their role as workers and housewives successfully [14].

Saxena and Rani studied family and employment of 40 employed and 40 unemployed middle class women in India for indicators of life satisfaction, and happiness including marital happiness. Results revealed that non-working women experienced greater life satisfaction and happiness than working women [15].

Pillai and Sen investigated the life of working women with regard to their dual role, as professionals and family care-takers. Results indicated that only as low as $7 \%$ of working women were able to harmonize their dual roles [16]. 
Aminabhav and Kulkarni studied the significance of difference between working women and housewives in their marital adjustment. The sample consisted of 50 working women and 50 housewives aged 23-55 yrs. Results revealed that working women had significantly higher marital adjustment than that of the housewives [17]. Aminabhav and Kulkarni also studied work status and dual role influences of 240 married working women non-working women aged 25-45 years selected from Government organizations of Jodhpur City on their mental health. Results indicated that non-working women had better understanding, more marital satisfaction and fulfilment of expectations; whereas the working women perceive little personal responsibilities for marital outcomes [17].

Hashmi explored the relationship between marital adjustment, stress and depression with a sample of 75 working married and 75 non-working married women aged between 18 to 50 years. Results indicated highly significant relationship between marital adjustment, depression and stress, implicating that, working married women had to face more problems in their married life as compared to non-working married women. The results further showed that highly educated working and non-working married women could perform well in their married life and they were free from depression as compared to educated working and non-working married women [18].

Borkar conducted a study to observe the marital adjustment of 120 working and non-working women in Pune city, Maharashtra, indicating that marital adjustment of non-working women is higher than nonworking women [19].

The problem of marital adjustment has in recent times become a very grave and important challenge, because of the complexities of work structure, ambiguity of roles of the spouses, multiple roles of the wife in relation to her in-laws, nuances of modern life, transnational co-habitation and emphasis on individual gratification.

\section{METHODOLOGY}

\section{Objective of study}

To measure Marital Adjustment and examine the extent to which it affects Mental Health of working women.

\section{Variables}

Dependent Variable: Mental Health

Independent Variable: Marital Adjustment

\section{Hypothesis}

Working married women with high Marital Adjustment will show positive relationship with Mental Health.

\section{Sample}

150 working women were selected by random sampling method from Mumbai across various occupations. The age range was from 26 to 35 years and the minimum educational qualification was graduation. The sample did not consider women who were divorced and also those who were widows.

\section{Tools Used}

\section{Marital Adjustment Questionnaire (MAQ)}

To study marital adjustment Rohatgi's Marital Adjustment Questionnaire (MAQ), 1999 was used. It has 25 items and 3 components namely Sexual, Social and Emotional. Each item is to be answered by YES or NO manner. Reliability of the test by Split Half method is 0.70 and by Retest method is 0.80 . Concurrent validity of the test with Marital Adjustment Inventory MAI [20] is 0.71

\section{Mental Health Checklist: (MHC)}

To study mental health, Mental health Inventory (MHC), was used. It has 11 items divided into 2 areas namely, Psychological(6items) and Somatic(5 items) rated on a 4 point scale ranging from 1 to 4 response 
categories, i.e. from 'Rarely', 'At times', 'Often' and 'Always', respectively. The reliability of split half method is 0.83 and test-retest reliability is 0.81 .

\section{RESULTS}

Table 1 - Correlation coefficient

\begin{tabular}{|l|l|l|}
\hline & MA & MH \\
\hline MA & 1.00 & 0.7003 \\
\hline MH & $0.7003^{*}$ & 1.00 \\
\hline
\end{tabular}

Table 2 - Correlation coefficient

\begin{tabular}{|l|l|l|}
\hline & MA & MH(Somatic aspect) \\
\hline MA & 1.00 & 0.6214 \\
\hline MH & $0.6214^{*}$ & 1.00 \\
\hline
\end{tabular}

Table 3 - Correlation coefficient

\begin{tabular}{|l|l|l|}
\hline & MA & MH(Psychological aspect) \\
\hline MA & 1.00 & 0.5122 \\
\hline MH & $0.5122^{*}$ & 1.00 \\
\hline
\end{tabular}

\section{DISCUSSION}

The correlational coefficients were calculated by applying the Pearson's product-moment formula. As shown in Table no.1, the co-relational co-efficient thus obtained was 0.70 . The co- relation indicates that there is very significant positive relationship between Marital Adjustment and Mental Health among working women. This finding is consistent with the study results of Hashmi H.A [18] who explored the relationship between M.A. \& M.H. of 150 working and non-working married women ( 75 working married women and 75 non-working married women) between 18 to 50 years. Their results showed that highly educated working and non-working married women can perform well in their married life and they are free from depression as compared to educated working and non-working women.

The results of the present study are also par with the study of Nathawat and Mathur (1993) in India about marital adjustment and subjective well-being in Indian-educated housewives and working women [8]. Their results indicated that working women had better marital adjustment and subjective well-being. Working women reported high scores on general health, life satisfaction and self-esteem measures \& lower scores on hopelessness, insecurity and anxiety whereas the housewives had lower scores on negative affect than the working women.

Also supportive to the findings, is the study of Goel and others (2013) [21] on Marital adjustment and Mental health among bank employees and doctors (40-55years) in Delhi which indicated that females were having better marital adjustment than males and make adjustment within the family responsibilities and work roles.

As shown in Table no.2 and Table No.3, the co-relational coefficients obtained between Marital Adjustment and Somatic aspect and Mental aspect of MHC were 0.62 and 0.51 respectively. The author argues that this slight difference between the correlation coefficients of the Somatic and Mental aspect can be attributed to physical strains on the working women due to the hassles of daily life namely traffic jams, delayed and overcrowded trains, humid weather conditions and other environmental factors which could 
trigger health problems. This is very typical in the metropolitan city of Mumbai which is characterised by a fast-paced life.

A plausible explanation for the overall significant co-relations obtained could be attributed to the fact that since working women are exposed to enriched environments than their non-working counterparts, in some form or the other, it helps them change their perceptions about life struggles and complications. This in turn, stimulates spiritual questions about existential concerns, thereby enabling the gradual development of positive adjustment patterns to cope up with their dual responsibilities. Even though the earlier research studies revealed conflicting results [22-24], the author argues that working married women who are well adjusted in their marital life will score higher on mental health parameters than non- working married women. The author opines that any work culture environment fosters the development of healthy attitude and perspective about life complexities. Thus eventually, working married women learn effective coping mechanisms to deal with work and family responsibilities.

\section{CONCLUSION}

There is a significant positive relationship between Marital Adjustment and Mental Health of working women.The positive relationship between Marital Adjustment and the Somatic aspect of Mental Health is slightly more significant than that between Marital Adjustment and the Physical Aspect of Mental Health. The sample of the present study comprised of only married working women. Future studies could include both married working and non-working women to observe the significance of difference between working women and housewives in their marital adjustment and subsequently on their mental health.

Marriage can have a very positive influence on mental health. For most women, marriage creates a new and important sense of identity and self-worth. Moreover, a spouse may provide emotional intimacy and support, fulfilling an essential human need for connection.

Consequently, married people may be happier, more satisfied, and less depressed than those who are unmarried. These emotional benefits may, in turn, improve their physical health, by reducing the stress, depression, and other mental health problems. Moreover, working women have many resources at their disposal for positive adjustment patterns. There is a common saying that "Marriages are made in heaven'. But they have to be executed and fulfilled on earth only. Considerable energy is devoted to the design and implementation of programs intended to prevent marital dysfunction before it occurs. Marital therapists and other life coach trainers should thus train married working women on resource and effective time management to balance their dual responsibilities to have an optimal effect on their marital harmony and thereby promote mental health. Such a step can certainly go a long way in saving marriages.

\section{REFERENCES}

1. Ramakrishna, P. School and Teacher's role in Students Mental Health. 2014

2. World Health Organization. Mental Health Report on the second session of the Expert Committee, Geneva: World Health Organization. 1951.

3. Kornhauser AW. Mental Health of the Industrial Worker. New York: Wiley; 1965

4. Sinha SP \& Mukherjee N. Marital adjustment and space orientation, J Soc Psychol 1990;130(5):633-9.

5. Singh A, Kiran UV. Impact of mother's status on personality of adolescents. International Journal of Advanced Scientific Technical Research 2014;1(4):86-99.

6. Devi K, Kiran UV. Work life balance of women workers in construction industry. Eur Acad Res 2014; 2(4):4932-46.

7. Lloyd S. The individual marriage and family. California: Wadsworth Publishing Company; 1980.

8. Nathawat SS, Mathur S. Marital adjustment and subjective well-being in Indian educated house wives and working women. J Psychol 2003;127(3):353-8.

9. Hoffman LW, Nye FI, Bahr SJ. Working mothers: An evaluative review of the consequences for wife, husband, and child. J Soc Issues 2006;12:109-18.

10. South SJ. Time-dependent effects of wives' employment on marital dissolution. Amer Sociolog Rev 2001;1:226-45.

11. Hansen HT. Unemployment and marital dissolution: A panel data study of Norway. Eur Sociol Rev 2005; 21(2):135-48 
12. Migon M. Women in multiple roles. Soc Welfare 2005;15:12-6.

13. Gupta GR, Ganguli HC. Marriage work interaction: A study of Indian women. Indian J Clin Psychol 1982;9:113-23.

14. Hemalatha P, Suryanarayana M. A study on reasons for taking up employment. Indian J Soc Work 1983;17(2):80-6.

15. Saxena M, Rani M. Life Satisfaction and Received Happiness as a Function of Family Structure and Employment of Women. Indian Psychol Abstr Rev 1996;4(2):343.

16. Pillai S, Sen AK. Work and Family: A Psycho-social Study of Dual Career Women. Indian J Clin Psychol 1998;25:165-9.

17. Aminabhav VA, Kulkarni VR. Marital adjustment of working women and housewives. J Proj Psychol Ment Health 2007;7(2):153-8.

18. Hashmi HA, Khurshid M, Hassan I. Marital adjustment, stress and depression among working and nonworking married women. Internet Journal of Medical Update 2007;2(1):19-26.

19. Borkar V. Marital Adjustment of Working and Non-working women. 2003 (Thesis).

20. Singh M, Singh G. Assessment of Mental Health Status of middle-age female school teachers of Varanasi city. Internet J Health 2006;5(1):6-9.

21. Goel S, Narang DK. Gender differences in marital adjustment, mental health and frustration reactions during middle age. J Humanities Soc Sci 2012;7(3):42-9.

22. Kumar P. Development and standardization of Mental Health Check-List (MHC). Psychological studies. 1991.

23. Kumar P. Mental Health Checklist. Agra, India: National Psychological Corporation. 1992:7-122.

24. Kumari KK. Marital adjustment and family resource management of working women among different income groups. International Referred Research Journal 2011;3(27):37-9.

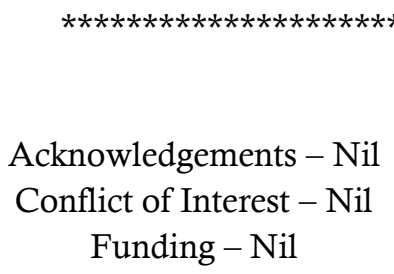

